Pacific Journal of Mathematics

REDUCIBLE OPERATORS WHOSE SPECTRA ARE
SPECIAL SETS 


\section{IRREDUCIBLE OPERATORS WHOSE SPECTRA ARE SPECTRAL SETS}

\section{Robert F. Olin and James E. Thomson}

In this note those compact subsets of the plane that are the spectra of irreducible subnormal operators are characterized.

In December 1977 John B. Conway presented a colloquium talk at Virginia Tech and asked, "Which compact subsets of the plane are the spectra of irreducible subnormal operators?" If the adjective irreducible is replaced by pure in this question, then Clancey and Putnam [2] have the following answer: A compact set $K$ is the spectrum of a pure subnormal operator if and only if for every open disc $\Delta$ that has a nonempty intersection with $K$, we have $R\left(K \cap \Delta^{-}\right) \neq C\left(K \cap \Delta^{-}\right)$. Similarly, our answer to Conway's question will be a function algebraic characterization. For the basic facts concerning this area we refer to [3] or [10].

If $\mathscr{H}$ is a separable Hilbert space the algebra of continuous operators on $\mathscr{H}$ will be denoted $\mathscr{B}(\mathscr{H})$. An operator $T \in \mathscr{B}(\mathscr{H})$ is irreducible if $\mathscr{H}$ has no nonzero subspace that is invariant under $T$ and its adjoint $T^{*}$. For the basic facts concerning subnormal operators we refer to [4]. If $T \in \mathscr{B}(\mathscr{H})$ then $\sigma(T)$ will denote the spectrum of $T$.

If $K$ is a compact subset of the plane, $\mathscr{R}(K)$ will denote the collection of rational functions with poles off $K$; the uniform closure of $\mathscr{R}(K)$ in $C(K)$, the algebra of continuous functions on $K$, is denoted $R(K)$. If $\varphi$ belongs to the maximal ideal space of $R(K)$, then there exists a point $z \in K$ such that $\varphi(f)=f(z)$ for all $f \in R(K)$. Hence the Gleason parts of $R(K)$ form a partition of $K$.

If $T \in \mathscr{B}(\mathscr{H})$ and $K$ is a compact set containing $\sigma(T)$, then $K$ is called a spectral set for $T$ if

$$
\|f(T)\| \leqq\|f\|_{K}
$$

for all $f \in \mathscr{R}(K)$. (Here $\|f\|_{K}$ denotes the sup norm of $f$ on $K$ ). If $K$ is a spectral set for $T$, it is easy to define $f(T)(\in \mathscr{B}(\mathscr{H}))$ for all $f \in R(K)$. A basic fact about a subnormal operator $S$ is that $\sigma(S)$ is a spectral set and equality holds in (i) with $K=\sigma(S)$ for all $f \in R(\sigma(S))$.

THEOREM 1. A compact set $K$ is the spectrum of an irreducible operator $T$ whose spectrum is a spectral set if and only if $R(K)$ has one nontrivial Gleason part $G$ and $G^{-}=K$. 
REMARK. In the sufficiency part of the proof the operator we construct is subnormal. Hence, the theorem answers the question of Conway. For the necessity part of the proof we need two (nontrivial) results and an elementary fact.

Fact. Suppose $K_{i}$ is a spectral set for $T_{i} \in \mathscr{B}\left(\mathscr{H}_{i}\right)$ and $K=$ $\left(\cup K_{i}\right)^{-}$is compact. Then $K$ is a spectral set for $T=\bigoplus T_{i}$.

We leave the proof to the reader.

THEOREM 2. (Mlak, Lautzenheiser, Seever). Let $K$ be a spectral set for $T \in \mathscr{B}(\mathscr{H})$ and let $G_{1}, G_{2}, \cdots$ be the nontrivial Gleason parts of $R(K)$. Then $T=N \oplus\left(\oplus_{i} T_{i}\right)$, where $N$ is a normal operator with spectrum contained in the boundary of $K$ and $G_{i}^{-}$is a spectral set for $T_{i}$. The proof of this and related results can be found in [5, $7,8,9]$.

The following theorem (combined with the fact and Theorem 2) guarantees that if $K$ is a spectral set for $T$ with at least two nontrivial Gleason parts $G_{1}, G_{2}$ for $R(K)$ such that $\sigma(T) \cap G_{i} \neq \varnothing$ $i=1,2$, then $T$ has a nontrivial reducing subspace.

THEOREM 3. (Melnikov). Let $G_{1}$ be a nontrivial Gleason part for $R(K)$. If $a \in G_{1}^{-} \backslash G_{1}$ then $a$ is a peak point. In particular, if $G_{2}$ is another Gleason part then $G_{2} \cap G_{1}^{-}=\varnothing$.

The proof of this result can be found in [6].

Proof of Theorem 1. The only thing left to establish is if $K$ is a compact set with one nontrivial Gleason part $G$ and $G^{-}=K$, then $K$ is the spectrum of an irreducible subnormal operator. Choose a sequence $\left\{z_{n}\right\}$ of points belonging to $G$ such that $\left\{z_{n}\right\}^{-}=K$. Let $\delta_{n}$ denote point mass measure at $z_{n}$. Fix $z_{0} \in G$.

For each $z_{n}$ choose a representing measure $\lambda_{n}$ for $R(K)$ at $z_{0}$ such that $\delta_{n}$ is absolutely continuous with respect to $\lambda_{n}$ (such a measure can be found by $[10$, p. 165]). Then

$$
\lambda=\sum_{n} \frac{\lambda_{n}}{2^{n}}
$$

is a representing measure for $R(K)$ at $z_{0}$ such that the support of $\lambda$ is $K$. Let $\mathscr{H}=R^{2}(\lambda)$, the $L^{2}(\lambda)$ closure of $R(K)$, and let $S$ be multiplication by $z$. Clearly $\sigma(S)=K$ so we need to show $S$ is irreducible.

Observe first that if $f \in R(K)$ then 


$$
\begin{aligned}
\left|f\left(z_{0}\right)\right| & =\left|\int f d \lambda\right| \\
& =|\langle f, 1\rangle| .
\end{aligned}
$$

(Here $\langle$,$\rangle denotes the inner product in R^{2}(\lambda)$.) It is now routine to show that

$$
\left\langle h_{1} h_{2}, 1\right\rangle=\left\langle h_{1}, 1\right\rangle\left\langle h_{2}, 1\right\rangle
$$

for all $h_{i} \in R^{2}(\lambda) \cap L^{\infty}(\lambda)$ for $i=1,2$.

Using the techniques of [12], one can show that the commutant of $S$ is the set $\left\{M_{\psi}: \psi \in R^{2}(\lambda) \cap L^{\infty}(\lambda)\right\}$, where $M_{\psi}$ denotes multiplication by $\psi$. Hence, if $P$ is a projection commuting with $S$, then $P=M_{f}$, where $f$ is the characteristic function of a Borel set $F$. By (ii) we see that $\langle f, 1\rangle$ equals zero or one. We assume that $\langle f, 1\rangle=1$ (otherwise we work with the projection $1-P=M_{1-f}$ ). Hence

$$
\begin{aligned}
1 & =\langle f, 1\rangle \\
& =\int_{F} d \lambda \\
& =\lambda(F) .
\end{aligned}
$$

Since $\lambda$ is a probability measure, $f=1$ almost everywhere; hence $P=1$.

Unfortunately there are no known topological criteria that characterize the sets which are nontrivial Gleason parts of $R(K)$. (Many necessary topological and measure theoretic facts are known: (1) $\bar{G}$ is connected. (2) $G$ is $\sigma$-compact. (3) $G$ has (area) density one at each of its points. (4) $G$ is area connected (consult [6]), etc.) However, the literature contains many interesting examples discussing various properties of these parts. Combining these examples with Theorem 1, one comes up with interesting operator theoretic consequences.

Fix an operator $T$ whose spectrum is a spectral set. If $\sigma(T)$ has two components of its interior, say $U_{1}$ and $U_{2}$ such that $\sigma(T)=$ $\left(U_{1} \cup U_{2}\right)^{-}$one may ask if $T=T_{1} \oplus T_{2}$ with $\sigma\left(T_{i}\right) \subset U_{i}^{-}$for $i=1,2$. However, since there exists a disconnected nontrivial part $[10$, Examples 26.24 and 26.25] the answer, in general, is no. (The first person to observe this phenomenon was Lautzenheiser in his thesis [5]. In this interesting work he also discusses how Theorem 2 subsumes many other known results.) One may also wonder if it is possible to write $T=T_{1} \oplus T_{2}$ with $\sigma\left(T_{1}\right) \subset(\text { int } \sigma(T))^{-}$and $\sigma\left(T_{2}\right) \subset$ $(\sigma(T) \backslash$ int $\sigma(T))$. Again the answer is no. Let $D=\{z:|z|<1\}$, $D_{+}=\{z \in D: \operatorname{Re} z>0\}$ and $D_{-}=\{z \in D: \operatorname{Re} z<0\}$. Construct a compact set $F$ from the closed unit disc $D^{-}$by removing pairwise disjoint 
open dises $D_{i}$ from $D_{+}$'such that int $\left(D_{+} \mid \cup D_{i}\right)=\varnothing$ and $\sum r_{i}<\infty$ $\left(r_{i}\right.$ is the radius of $D_{i}$ ). Using Theorem 2 in [11] and Theorem 3 in [1], we can construct $F$ such that zero is not a peak point of $R(F)$. Let $K=G^{-}$where $G$ is the nontrivial part of $R(F)$ containing zero. (Note: $G \cap D_{+} \neq \varnothing$ and $G \supset D_{-}$)

\section{REFERENCES}

1. A. Browder, Point derivations on function algebras, J. Functional Anal., 1 (1967), 22-27.

2. K. Clancey and C. R. Putnam, The local spectral behavior of completely subnormal operators, Trans. Amer. Math. Soc., 163 (1972), 239-244.

3. T. Gamelin, Uniform Algebras, Printice-Hall, Englewood Cliffs, NJ., 1969.

4. P. Halmos, A Hilbert space problem book, Van Nostrand, Princeton, NJ., 1967.

5. R. Lautzenheiser, Spectral sets, reducing subspaces and function algebras, Thesis, Indiana University, 1973.

6. M. Melnikov, The Gleason parts of the algebra $R(X)$, Math. Sb., 101 (143) (1976), 293-300.

7. W. Mlak, Decompositions and extensions of operator valued representations of function algebras, Acta Sci. Math. (Szeged), 30 (1969), 181-193.

8. —, Partitions of spectral sets, Ann. Pol. Math., 25 (1972), 273-280.

9. G. L. Seever, Operator representations of uniform algebras. I., preprint.

10. E. L. Stout, The theory of uniform algebras, Bogden and Quigley, Tarrytown-onHudson NJ., 1971,

11. J. Wermer, Bounded point derivations on certain Banach algebras, J. Functional Anal., 1 (1967), 28-36.

12. T. Yoshino, Subnormal operators with a cyclic vector, Tohoku Math. J., 21 (1969), 47-55.

Received October 10, 1979. This research was supported in part by the National Science Foundation under Grant No. MCS77-00966.

Current address: Virginia Tech. Blacksburg, Virginia 24061 


\section{PACIFIC JOURNAL OF MATHEMATICS}

\section{EDITORS}

DONALD BABBITT (Managing Editor)

University of California

Los Angeles, CA 90024

Hugo RossI

University of Utah

Salt Lake City, UT 84112

C. C. MOORE and ANDREW OGG

University of California

Berkeley, CA 94720

\section{J. DugundjI}

Department of Mathematics

University of Southern California

Los Angeles, CA 90007

R. FinN and J. Milgram

Stanford University

Stanford, CA 94305

\section{ASSOCIATE EDITORS}
E. F. BeCKENBACH
B. H. Neumann
F. WoLF
K. YoSHIDA

\section{SUPPORTING INSTITUTIONS}

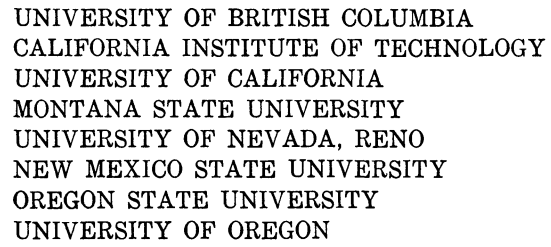

UNIVERSITY OF BRITISH COLUMBIA CALIFORNIA INSTITUTE OF TECHNOLOGY UNIVERSITY OF CALIFORNIA MONTANA STATE UNIVERSITY UNIVERSITY OF NEVADA, RENO NEW MEXICO STATE UNIVERSITY OREGON STATE UNIVERSITY UNIVERSITY OF OREGON

\author{
UNIVERSITY OF SOUTHERN CALIFORNIA \\ STANFORD UNIVERSITY \\ UNIVERSITY OF HAWAII \\ UNIVERSITY OF TOKYO \\ UNIVERSITY OF UTAH \\ WASHINGTON STATE UNIVERSITY \\ UNIVERSITY OF WASHINGTON
}

The Supporting Institutions listed above contribute to the cost of publication of this Journal, but they are not owners or publishers and have no responsibility for its content or policies.

Mathematical papers intended for publication in the Pacific Journal of Mathematics should be in typed form or offset-reproduced, (not dittoed), double spaced with large margins. Please do not use built up fractions in the text of the manuscript. However, you may use them in the displayed equations. Underline Greek letters in red, German in green, and script in blue. The first paragraph or two must be capable of being used separately as a synopsis of the entire paper. Please propose a heading for the odd numbered pages of less than 35 characters. Manuscripts, in triplicate, may be sent to any one of the editors. Please classify according to the scheme of Math. Reviews, Index to Vol. 39. Supply name and address of author to whom proofs should be sent. All other communications should be addressed to the managing editor, or Elaine Barth, University of California, Los Angeles, California, 90024.

50 reprints to each author are provided free for each article, only if page charges have been substantially paid. Additional copies may be obtained at cost in multiples of 50 .

The Pacific Journal of Mathematics is issued monthly as of January 1966. Regular subscription rate: $\$ 84.00$ a year (6 Vols., 12 issues). Special rate: $\$ 42.00$ a year to individual members of supporting institutions.

Subscriptions, orders for numbers issued in the last three calendar years, and changes of address shoud be sent to Pacific Journal of Mathematics, P.O. Box 969, Carmel Valley, CA 93924, U.S.A Old back numbers obtainable from Kraus Periodicals Co., Route 100, Millwood, NY 10546.

PUBLISHED BY PACIFIC JOURNAL OF MATHEMATICS, A NON-PROFIT CORPORATION

Printed at Kokusai Bunken Insatsusha (International Academic Printing Co., Ltd.). 8-8, 3-chome, Takadanobaba, Shinjuku-ku, Tokyo 160, Japan. 


\section{Pacific Journal of Mathematics}

\section{Vol. 91, No. 2 December, 1980}

Victor P. Camillo and Julius Martin Zelmanowitz, Dimension modules ... . . 249

Yonina S. Cooper, Stable sequences in pre-abelian categories ........... 263

Chandrakant Mahadeorao Deo and H. Ship-Fah Wong, On Berry-Esseen approximation and a functional LIL for a class of dependent random fields.........................................

H. P. Dikshit and S. N. Dubey, $|C, 1|$ summability of series associated with

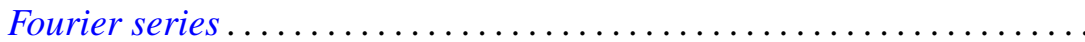

M. Edelstein, On the homomorphic and isomorphic embeddings of a semiflow into a radial flow.

Gilles Godefroy, Compacts de Rosenthal ..................... 293

James Guyker, Commuting hyponormal operators ................ 307

Thomas Eric Hall and Peter R. Jones, On the lattice of varieties of bands of

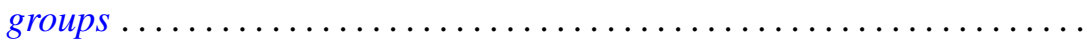

Taqdir Husain and Saleem H. Watson, Topological algebras with orthogonal Schauder bases ....................................

V. K. Jain, Some expansions involving basic hypergeometric functions of two variables. . .

Joe W. Jenkins, On group actions with nonzero fixed points ........... 363

Michael Ellsworth Mays, Groups of square-free order are scarce ........ 373

Michael John McAsey, Canonical models for invariant subspaces... 377

Peter A. McCoy, Singularities of solutions to linear second order elliptic partial differential equations with analytic coefficients by approximation methods...

Terrence Millar, Homogeneous models and decidability.

Stephen Carl Milne, A multiple series transformation of the very well poised

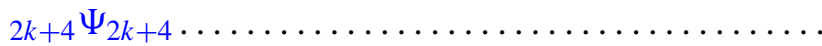

Robert Olin and James E. Thomson, Irreducible operators whose spectra are spectral sets...

Robert John Piacenza, Cohomology of diagrams and equivariant singular

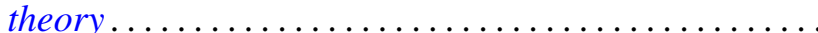

Louis Jackson Ratliff, Jr., Integrally closed ideals and asymptotic prime divisors

Robert Breckenridge Warfield, Jr., Cancellation of modules and groups and stable range of endomorphism rings.................

B. J. Day, Correction to: "Locale geometry" ...............

Stanley Stephen Page, Correction to: "Regular FPF rings" ... 